\title{
Supplemental Choline During the Periweaning Period Protects Against Trace Conditioning Impairments Attributable to Post- Training Ethanol Exposure in Adolescent Rats
}

Pamela S. Hunt

William \& Mary, pshunt@wm.edu

Follow this and additional works at: https://scholarworks.wm.edu/aspubs

\section{Recommended Citation}

Hunt, P. S. (2012). Supplemental choline during the periweaning period protects against trace conditioning impairments attributable to post-training ethanol exposure in adolescent rats. Behavioral neuroscience, 126(4), 593. 


\title{
BRIEF COMMUNICATION
}

\section{Supplemental Choline During the Periweaning Period Protects Against Trace Conditioning Impairments Attributable to Post-Training Ethanol Exposure in Adolescent Rats}

\author{
Pamela S. Hunt \\ College of William \& Mary
}

\begin{abstract}
Supplemental choline during early stages of development can result in long-lasting improvements to memory function. In addition, pre- or postnatal choline has been shown to be protective against some of the adverse effects of early alcohol exposure. The present experiment examined whether supplemental choline given to rats would protect against the effects of posttraining alcohol administration on trace fear conditioning. Posttraining alcohol exposure in adolescent rats results in poor performance in this hippocampus-dependent task, although delay conditioning is unaffected. Here, rats were given an s.c. injection of either saline or choline chloride daily on postnatal days (PD) 15-26. On PD 30 subjects were trained in a trace fear conditioning procedure. For the next 3 days animals were administered $2.5 \mathrm{~g} / \mathrm{kg}$ ethanol or water control, and conditional stimulus (CS)-elicited freezing was measured on PD 34. Results indicated that posttraining alcohol disrupted the expression of trace conditioning and that supplemental choline on PD 15-26 was protective against this effect. That is, choline-treated animals subsequently given posttraining ethanol performed as well as animals not given ethanol. These results indicate that supplemental choline given during the periweaning period protects against ethanol-induced impairments in a hippocampus-dependent learning task. Findings contribute to the growing literature showing improvements in learning and memory in subjects given extra dietary choline during critical periods of brain development.
\end{abstract}

Keywords: choline, hippocampus, frontal cortex, fear conditioning, alcohol, adolescence

Choline is an essential nutrient that has been shown to be particularly important during early brain development (Meck \& Williams, 2003; Zeisel, 2004). It not only serves as a precursor to the neurotransmitter acetylcholine, which can itself have neurotrophic effects, but it is also involved in the formation of major constituents of cell membranes and intracellular signaling chemicals. Extra dietary choline, given pre- and/or postnatally to rats, can result in improved learning and memory. Supplementation with choline can speed up the normal ontogeny of spatial memory (Mellott, Williams, Meck \& Blusztajn, 2004), can lead to superior spatial (Meck, Smith \& Williams, 1989; Tees \& Mohammadi, 1999) and temporal (Meck \& Williams, 1997a) memory performance in adults, and can mitigate aspects of cognitive decline in rodents that result from normal aging processes (Glenn et al., 2008; Meck \& Williams, 1997b).

Extra dietary choline given pre- or postnatally can also be protective against the adverse effects of alcohol in rodent models of fetal alcohol exposure. Several studies now show that choline supplemen-

This article was published Online First June 11, 2012.

This research was supported by National Institutes of Health grant AA015343.

Correspondence concerning this article should be addressed to Pamela S. Hunt, Department of Psychology, College of William \& Mary, PO Box 8795, Williamsburg, VA 23187-8795. E-mail: pshunt@wm.edu tation can attenuate or even reverse many of the negative effects of alcohol exposure on learning and memory processes. For example, deficits in spatial learning in the Morris water maze (Ryan, Williams \& Thomas, 2008), visual discrimination learning (Thomas, La Fiette, Quinn \& Riley, 2000), reversal learning (Thomas, Garrison \& O'Neill, 2004), and trace conditioning (Thomas \& Tran, 2012; Wagner \& Hunt, 2006) caused by pre- or neonatal ethanol exposure can be significantly reduced by extra choline given during or even after the ethanol exposure period. The extent to which supplemental choline given during critical periods of brain development can protect against other adverse events has not received as much attention. However, choline supplementation has been shown to protect against some of the effects of prenatal nicotine in monkeys (Slotkin et al., 2005), seizure-induced impairments in spatial memory (Yang et al., 2000), and hippocampal neural degeneration in rats (Wong-Goodrich, Glenn, Mellott, Liu, Blusztajn \& Williams, 2008) and can protect against NMDA antagonist-mediated excitotoxicity in some brain regions (Guo-Ross et al., 2002). Further, reports have shown improved behavioral outcomes in transgenic mouse models of Down (Moon et al., 2010) and Rett (Nag \& Berger-Sweeney, 2007) syndromes by perinatal choline supplementation.

Hunt, Levillain, Spector, and Kostelnik (2009) reported that posttraining exposure to alcohol in adolescent rats produces impairments in the expression of a previously acquired hippocampal 
learning task, trace fear conditioning. However, delay fear conditioning, a nonhippocampal variant of the procedure, was unaffected by posttraining ethanol. Binge-like alcohol exposure is known to produce profound changes in hippocampal memory, whether that alcohol exposure occurs during the neonatal period (Goodlett \& Johnson, 1997), adolescence (Osborne \& Butler, 1983) or adulthood (Obernier, White, Swartzwelder \& Crews, 2002). Such exposure can result in changes in cell numbers and densities in hippocampal regions (Bonthius \& West, 1990; Crews, Braun, Hoplight, Switzer \& Knapp, 2000), as well as changes in hippocampal neurogenesis (Crews, Mdzinarishvili, Kim, He \& Nixon, 2006; Hamilton et al., 2011). Ethanol can also interfere with induction of LTP, especially in the adolescent hippocampus (Pyapali, Turner, Wilson \& Swartzwelder, 1999). Thus, binge-like ethanol exposure during many different developmental periods can produce significant disruptions in hippocampal anatomy and function.

Given that extra dietary choline can attenuate or perhaps even prevent ethanol-induced behavioral abnormalities in models of fetal alcohol exposure (Ryan et al., 2008; Thomas, Garrison \& O'Neill, 2004; Wagner \& Hunt, 2006), and may be protective against other toxic events (e.g., Guo-Ross et al., 2002; Slotkin et al., 2005), the present study was conducted to examine whether supplemental choline would also be protective against the impairing effects of posttraining ethanol exposure during adolescence, as reported by Hunt et al. (2009). Choline was administered daily on postnatal days (PD) 15-26, a period sensitive to some memoryenhancing effects of choline (Meck, Williams, Cermak \& Blusztajn, 2008). Animals were trained in a trace conditioning procedure on PD 30. Ethanol was given for three days after training, and subjects were tested for conditional stimulus (CS)-elicited freezing on PD 34. Delay conditioning was not used because this type of learning is unaffected by posttraining ethanol exposure (Hunt et al., 2009).

\section{Method}

\section{Subjects}

The subjects were 48 Sprague-Dawley rats derived from six litters (24 male, 24 female), born and reared in the animal vivarium at the College of William \& Mary. Male and female breeders (Charles River Laboratories, Wilmington, MA) were maintained together in $50.8 \times 40.6 \times 21.6 \mathrm{~cm}$ clear polycarbonate cages. Cages were equipped with stainless steel lids that accommodated high-protein rat chow (LabDiet Formula 5008; 2000 ppm choline) and glass water bottles. Pine shavings served as bedding material. Cages were checked daily for pups, and the day of birth was designated as PD 0. Litters were culled to eight pups on PD 2. Pups were weaned from the home cage on PD 21, at which time they were group housed with siblings in identical polycarbonate cages for the duration of the experiment. The vivarium was maintained on a 14:10 h light:dark cycle, with light onset at $0600 \mathrm{~h}$. All procedures occurred during the light phase of the cycle and were approved by the Institutional Animal Care and Use Committee of the College of William \& Mary.

\section{Apparatus}

Training occurred in two identical $38.0 \times 26.0 \times 22.0 \mathrm{~cm}$ modified Skinner boxes. The two shorter walls were made of aluminum and the two longer walls and top were made of clear Plexiglas. The floor was constructed of $5 \mathrm{~mm}$ stainless steel bars, spaced $1.5 \mathrm{~cm}$ apart, connected to a constant current shock generator. The unconditioned stimulus (US) was a 1-s, 0.5-mA shock delivered through the grid floor. The CS was produced by a $25-\mathrm{W}$ white bulb that was located behind one of the longer clear walls. The CS was $10 \mathrm{~s}$ in duration and flashed at a rate of two times per second. The conditioning chambers were housed within sound insulated shells. A 4-W red bulb was mounted on an inside wall of the shell and provided low-level illumination throughout the training sessions. A PC computer was used to interface Coulbourn Instruments (Allentown, PA) software and hardware and controlled all stimulus presentations.

Testing occurred in a novel context located in a different room in the laboratory. The two test chambers were $29.0 \times 21.5 \times 46.5$ $\mathrm{cm}$ and were made of clear Plexiglas. The top and bottom of each chamber was open. The bottom $11 \mathrm{~cm}$ of each chamber was constructed of horizontally arranged 5-mm stainless steel rods spaced $1.5 \mathrm{~cm}$ apart. The chambers rested on Plexiglas floors covered with brown paper. The chambers were housed in soundattenuating shells, each with a 7-W white bulb mounted on an inner wall that provided low-level illumination throughout the test session. The CS used for test was identical to that used during training. Test sessions were videotaped using Sony videocameras (Model CCD-TRV67).

\section{Procedure}

The eight pups from each litter were pseudorandomly assigned to one of four treatment groups comprising a 2 (saline vs. choline) $\times 2$ (water vs. ethanol) factorial design. One male and one female pup per litter were assigned to each group. Each group had $n=12$ animals, with equal numbers of males and females in each.

Choline administration. Choline was administered via subcutaneous injection, once daily, beginning on PD 15 and continuing through PD 26. Meck et al. (2008) have reported that this period of postnatal development encompasses a sensitive period for choline's beneficial effects on some brain functions. Choline chloride (Sigma, St. Louis, MO) was dissolved in saline to produce an $18.8 \mathrm{mg} / \mathrm{ml}$ solution and was injected in a constant volume of $0.1 \mathrm{ml}$ per subject per day. This procedure was based on one used by Thomas, O'Neill, and Dominguez (2004). Control animals were injected with an equal volume of the saline vehicle. Injections were achieved using 30-gauge needles attached to 1-cc syringes.

Trace fear conditioning. Animals were trained on PD 30 in a single 30-min session. Subjects were given five CS-US pairings, with intertrial intervals ranging from 200-300 s. Each trial consisted of a 10-s presentation of the CS followed, $10 \mathrm{~s}$ later, by onset of the US. Thus, the trace interval was $10 \mathrm{~s}$. Training sessions began with a 5-min adaptation period, and subjects were removed from the training context 5 min after the last US.

Posttraining ethanol administration. Procedures used were based on those described by Hunt et al. (2009). Ethanol was administered via oral gavage once daily on PD 31-33. The dose was $2.5 \mathrm{~g} / \mathrm{kg}$ per day of a $20 \% \mathrm{vol} / \mathrm{vol}$ solution dissolved in tap 
water. Controls were given an equal volume of the tap water vehicle. Intubations were achieved using polyethylene tubing (PE50; Intramedic, Becton Dickinson and Co., Sparks, MD) attached to 5 -ml syringes.

Testing. On PD 34, approximately $24 \mathrm{~h}$ after the final ethanol dose, all animals were tested for CS-elicited freezing and the test session was videotaped. After a 5-min adaptation period, subjects were given five CS alone trials (no shocks were given during test), separated by 60 - to 120 -s intervals. Videotaped records of the test session were subsequently scored for freezing behavior by an observer blind to the experimental treatment of the animals. Freezing was defined as the absence of all visible movements except those required for respiration (Fanselow, 1980). Freezing was scored for each test trial using a time sampling procedure. For $10 \mathrm{~s}$ before CS onset (pre-CS), and for the $10 \mathrm{~s}$ of the CS, animals were briefly observed at 2-s intervals and a judgment was made as to whether the animal was freezing or not. The percentage of intervals scored as freezing during each epoch was calculated $(0-100 \%)$.

\section{Results}

\section{Body Weights}

Body weights were recorded on the first and last day of choline administration, PD 15 and 26. A mixed-factor ANOVA was used to assess the effects of choline on body weights, with choline and sex serving as between-groups factors and day as a within-group factor. The analysis yielded main effects of day, $F(1,44)=$ $4024.18, p<.001$, and sex, $F(1,44)=10.08, p<.01$, as well as a Day $\times$ Sex interaction, $F(1,44)=12.33, p<.001$. There was no effect of choline on body weights. On PD 15 males and females weighed the same $(M=42.39 \pm 0.71 \mathrm{~g})$, but by PD 26 the males weighed more than the females $\left(M_{\text {males }}=94.04 \pm 1.30 \mathrm{~g}\right.$; $M_{\text {females }}=87.07 \pm 1.40 \mathrm{~g}$ ).

Weights recorded during the ethanol administration procedure (PD 31-33) were also analyzed using mixed-factor ANOVA. The analysis yielded significant main effects of sex, $F(1,40)=26.21$, $p<.001$, and day, $F(1,80)=584.46, p<.001$, and a Sex $\times$ Day interaction, $F(2,80)=17.69, p<.001$. There was no effect of ethanol on body weights. Females overall weighed less than males and also gained less weight from PD 31 through 33.

\section{Pre-CS Freezing}

Percent pre-CS freezing was averaged across the five test trials and analyzed using a 2 (choline) $\times 2$ (ethanol) $\times 2$ (sex) betweengroups ANOVA. The analysis yielded no significant effects or interactions. Freezing before CS onset was relatively low and was equivalent across groups. Levels of pre-CS freezing are shown in Figure 1 (white bars).

\section{CS Freezing}

Percent freezing during the CS is also shown in Figure 1 (black bars). CS freezing was averaged across the five test trials and also analyzed using a $2 \times 2 \times 2$ ANOVA that was followed by Newman-Keuls post hoc tests $(p<.05)$. The ANOVA yielded a main effect of choline, $F(1,38)=4.14, p<.05$, and a Choline $\times$

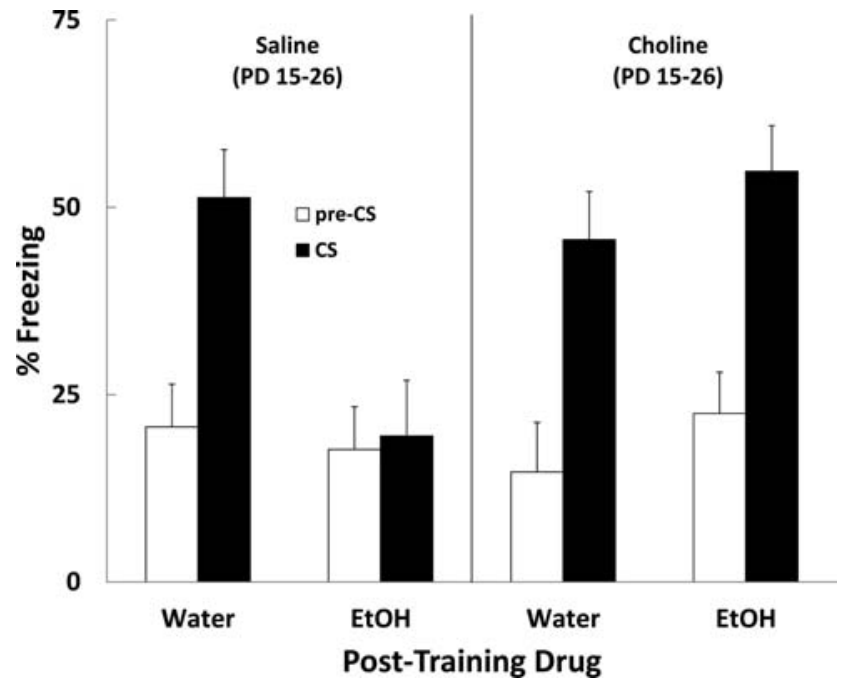

Figure 1. Mean ( \pm SEM) \% freezing during a baseline (pre-CS) period and during the light CS. Data are the \% of intervals scored as freezing using a time-sampling procedure. Subjects were given s.c. saline or choline injections on postnatal days (PD) 15-26. On PD 30 subjects were trained using a trace fear conditioning procedure and were subsequently given i.g. water or $2.5 \mathrm{~g} / \mathrm{kg}$ ethanol $(\mathrm{EtOH})$ for three days. Subjects were tested for freezing on PD 34, approximately $24 \mathrm{~h}$ after the final ethanol exposure. Pre-CS freezing was equivalent in all groups. Post-training ethanol impaired trace conditioned responding (group Saline-EtOH), and supplemental choline prevented this effect (group Choline-EtOH).

Ethanol interaction, $F(1,38)=8.78, p<.01$. There were no effects of sex on CS freezing. Posttraining ethanol exposure resulted in impaired expression of trace conditioning, evident in the difference in CS freezing between Groups Saline-Water and Saline-Ethanol. However, prior supplemental choline injections prevented this impairment by ethanol. Group Choline-Ethanol did not differ from Group Choline-Water and responded with more CS freezing than Group Saline-Ethanol.

\section{Discussion}

Results of this experiment demonstrate that supplemental choline given during the period surrounding weaning, PD 15-26, is protective against memory impairments induced by posttraining ethanol exposure in adolescent rats. The present findings replicate those of a previous study from this lab (Hunt et al., 2009) that ethanol exposure occurring after training induces deficits in performance in a trace fear conditioning task. Hunt et al. (2009) also reported that posttraining ethanol had no effect on the expression of delay fear conditioning, a nonhippocampal version of fear conditioning. The present results further indicate that animals given supplemental choline injections on PD 15-26 failed to exhibit the ethanol-induced impairment in trace conditioning. Thus, supplemental choline is protective against the effects of adolescent ethanol exposure on hippocampus-dependent learning.

The effects of posttraining ethanol on the expression of trace fear does not appear to result from acute ethanol withdrawal effects. Hunt et al. (2009, Experiment 3) trained subjects in this trace procedure on PD 30, gave ethanol on PD 32-34, and tested subjects on PD 35. In this case, no ethanol-induced impairment in 
trace fear was observed. In this procedure, the animals were also tested $24 \mathrm{~h}$ after a 3-day ethanol administration regimen. It is also possible that the choline supplementation protocol affected ethanol metabolism, such that blood-alcohol levels (BALs) were not as high in choline-supplemented rats. Although BALs were not recorded in this experiment, Thomas and colleagues (e.g., Thomas, Garrison \& O'Neill, 2004; Thomas \& Tran, 2012) have reported that neonatal choline supplementation does not affect peak bloodalcohol levels. Although Thomas' results suggest that extra choline does not affect ethanol metabolism, the subjects in those experiments were much younger than those in the present study. Measuring BALs with the current choline and ethanol treatment protocols would be necessary to directly assess this possibility.

Acquisition in trace conditioning procedures is known to depend on intact hippocampal and prefrontal cortical functioning. Involvement of the hippocampus has been demonstrated in work using both pre- (McEchron, Bouwmeester, Tseng, Weiss \& Disterhoft, 1998) and posttraining (Quinn, Oommen, Morrison \& Fanselow, 2002) hippocampal lesions, and pharmacological blockade of muscarinic cholinergic receptors (Anagnostaras, Maren, Sage, Goodrich \& Fanselow, 1999; Hunt \& Richardson, 2007) or NMDA receptors (Quinn, Loya, Ma \& Fanselow, 2005). The frontal cortex, in particular the medial prefrontal cortex (mPFC), also appears important for trace conditioning. Cells within this region exhibit bouts of activity during the trace interval in a fear conditioning procedure (Gilmartin \& McEchron, 2005). Pretraining lesions of the mPFC also block acquisition of trace conditioning (Guimarais, Gregorio, Cruz, Guyon \& Moita, 2011), although lesions made shortly after training are reported to have no effect (Quinn, Ma, Tinsley, Koch \& Fanselow, 2008). Importantly, in all of these instances where trace conditioning is significantly disrupted, delay conditioning is typically spared. These findings argue for specific roles for the hippocampus and prefrontal cortex in trace learning, as opposed to fear conditioning more generally. As described previously, it is possible that posttraining ethanol produces effects on trace conditioning because of its disruption in hippocampal and/or prefrontal function.

How choline is having its protective effects against ethanol amnesia is unclear. Supplemental choline treatments lead to improvements in cholinergic functioning, including an enhancement of depolarization-evoked ACh release in hippocampus and frontal cortex (Napoli, Blusztajn \& Mellott, 2008) and decreases in AChE and ChAT activity in these same regions (Cermak, Holler, Jackson \& Blusztajn, 1998). Choline supplementation has also been found to increase muscarinic receptor binding and levels of neurotrophic factors (e.g., BDNF, NGF) in hippocampus and frontal cortex (Meck et al., 1989; Napoli et al., 2008; Sandstrom, Loy \& Williams, 2002). Choline also increases neurogenesis in the dentate gyrus (Glenn, Gibson, Kirby, Mellott, Blusztajn \& Williams, 2007), which is important for trace conditioning (Shors, Miesegaes, Beylin, Zhao, Rydel \& Gould, 2001) and lowers the threshold for LTP induction in the hippocampus (Pyapali, Turner, Williams, Meck \& Swartzwelder, 1998). This suggests enhanced and more efficient cholinergic transmission in these brain regions that are important to trace fear conditioning after choline supplementation treatment.

Flesher, Butt, and Kinney-Hurd (2011) reported increased acetylcholine release in hippocampus and $\mathrm{mPFC}$ in an appetitive trace conditioning procedure that was not observed in delay condition- ing. Experience-dependent increases in acetylcholine release appears necessary for encoding, while decreases in release have been implicated in consolidation (Micheau \& Marighetto, 2011). Further, hippocampal muscarinic receptors are involved in NMDA receptor-dependent synaptic plasticity (Sánchez et al., 2009; Scheiderer et al., 2008). As described previously, ethanol may have many different effects that compromise trace fear conditioning, either within the hippocampus, the frontal cortex, or both. Of interest is that many of the processes that are negatively affected by ethanol are similar to those known to be enhanced by early choline supplementation (e.g., NMDA receptor-dependent synaptic plasticity, hippocampal neurogenesis).

While the studies cited above used prenatal or pre + postnatal choline administration, it is possible that long-term enhancements in cholinergic transmission could result from choline supplementation limited to the postnatal period. Along with the substantial postnatal development of the hippocampus (Altman \& Bayer, 1975) and frontal cortex (Crews, He \& Hodge, 2007), the basal forebrain cholinergic system undergoes considerable postnatal maturation during the first 4 weeks of life. Changes occurring during this time include increases in cholinergic cell body size and dendritic branching (Gould, Farris \& Butcher, 1989), increased levels of ACh and ChAT (Coyle \& Yamamura, 1976), and increases in the high-affinity choline uptake system and AChE activity (Abreu-Villaça, Filgueiras \& Manhaes, 2011; Villalobos, Rios \& Barbosa, 2001). Muscarinic receptor binding also develops during this period, achieving adult-like levels by about PD 28 (Coyle \& Yamamura, 1976). Extra choline during this postnatal period may produce a cholinergic system that is more resistant to some adverse events (Meck et al., 1989; 2008; Napoli et al., 2008), although this has not been evaluated explicitly. The present results suggest that in the normally developing animal, posttraining ethanol exposure using the procedures described here is sufficient to impair some aspect of processing that result in deficits in the expression of trace fear, but that postnatal supplementation with choline yields a system that is protected in some way against the memory-impairing effects of high doses of ethanol.

A large amount of research has now shown that choline supplementation can produce benefits to brain function, but its limits need also be identified. For example, choline seems to have no beneficial effect on motor coordination deficits (Thomas, O'Neill \& Dominguez, 2004) or impaired delay eyeblink conditioning (Thomas \& Tran, 2012) caused by neonatal alcohol exposure, even though the choline treatment procedures were the same as those reported to successfully reverse other behavioral impairments resulting from alcohol exposure (cf. trace eyeblink conditioning; Thomas \& Tran, 2012). In the present experiment, the choline treatment did not improve freezing in the Choline-Water group. This lack of effect could be the result of the training procedures producing asymptotic learning in the adolescent animal (see also Barnet \& Hunt, 2005). Examining any potential enhancements in hippocampal learning processes by supplemental choline in otherwise untreated animals may be informative as to its neural basis (Mellott et al., 2004). This could easily be accomplished within the present paradigm by variations in the training procedure used or increasing the complexity of the task with the use of longer trace intervals (Chowdhury, Quinn \& Fanselow, 2005). Also, whether the benefits of periweaning choline like those reported here would extend to situations involving higher doses of ethanol, ethanol 
given for longer durations, or ethanol given at other times relative to learning (Crews et al., 2000; Yttri, Burk \& Hunt, 2004) has not been evaluated. Nonetheless, the present experiment does indicate that extra dietary choline during this particular sensitive period of development affords at least some protection against ethanol's memory-impairing effects in adolescent rats.

\section{References}

Abreu-Villaça, Y., Filgueiras, C. C., \& Manhaes, A. C. (2011). Developmental aspects of the cholinergic system. Behavioural Brain Research, 221, 367-378. doi:10.1016/j.bbr.2009.12.049

Altman, J., \& Bayer, S. (1975). Postnatal development of the hippocampal dentate gyrus under normal and experimental conditions. In R. L. Isaacson \& K. H. Pribram (Eds.), The hippocampus: Structure and development (Vol. 1, pp. 95-122). New York, NY: Plenum.

Anagnostaras, S. G., Maren, S., Sage, J. R., Goodrich, S., \& Fanselow, M. S. (1999). Scopolamine and Pavlovian fear conditioning in rats: Dose-effect analysis. Neuropsychopharmacology, 21, 731-744. doi: 10.1016/S0893-133X(99)00083-4

Barnet, R. C., \& Hunt, P. S. (2005). Trace and long-delay fear conditioning in the developing rat. Learning \& Behavior, 33, 437-443. doi:10.3758/ BF03193182

Bonthius, D. J., \& West, J. R. (1990). Alcohol-induced neuronal loss in developing rats: Increased brain damage with binge exposure. Alcoholism: Clinical and Experimental Research, 14, 107-118. doi:10.1111/ j.1530-0277.1990.tb00455.x

Cermak, J. M., Holler, T., Jackson, D. A., \& Blusztajn, J. K. (1998). Prenatal availability of choline modifies development of the hippocampal cholinergic system. FASEB Journal, 12, 349-357.

Chowdhury, N., Quinn, J. J., \& Fanselow, M. S. (2005). Dorsal hippocampus involvement in trace fear conditioning with long, but not short, trace intervals in mice. Behavioral Neuroscience, 119, 1396-1402. doi: 10.1037/0735-7044.119.5.1396

Coyle, J. T., \& Yamamura, H. I. (1976). Neurochemical aspects of the ontogenesis of cholinergic neurons in the rat brain. Brain Research, 118, 429-440. doi:10.1016/0006-8993(76)90310-3

Crews, F., He, J., \& Hodge, C. (2007). Adolescent cortical development: A critical period of vulnerability for addiction. Pharmacology, Biochemistry and Behavior, 86, 189-199. doi:10.1016/j.pbb.2006.12.001

Crews, F. T., Braun, C. J., Hoplight, B., Switzer, R. C., \& Knapp, D. J. (2000). Binge ethanol consumption causes differential brain damage in young adolescent rats compared with adult rats. Alcoholism: Clinical and Experimental Research, 24, 1712-1723. doi:10.1111/j.15300277.2000.tb01973.x

Crews, F. T., Mdzinarishvili, A., Kim, D., He, J., \& Nixon, K. (2006). Neurogenesis in adolescent brain is potently inhibited by ethanol. Neuroscience, 137, 437-445. doi:10.1016/j.neuroscience.2005.08.090

Fanselow, M. S. (1980). Conditional and unconditional components of post-shock freezing. Pavlovian Journal of Biological Sciences, 15, 177182.

Flesher, M. M., Butt, A. E., \& Kinney-Hurd, B. L. (2011). Differential acetylcholine release in the prefrontal cortex and hippocampus during Pavlovian trace and delay conditioning. Neurobiology of Learning and Memory, 96, 181-191. doi:10.1016/j.nlm.2011.04.008

Gilmartin, M. R., \& McEchron, M. D. (2005). Single neurons in the medial prefrontal cortex of the rat exhibit tonic and phasic coding during trace fear conditioning. Behavioral Neuroscience, 119, 1496-1510. doi: 10.1037/0735-7044.119.6.1496

Glenn, M. J., Gibson, E. M., Kirby, E. D., Mellott, T. J., Blusztajn, J. K., \& Williams, C. L. (2007). Prenatal choline availability modulates hippocampal neurogenesis and neurogenic responses to enriching experiences in adult female rats. European Journal of Neuroscience, 25, 2473-2482. doi:10.1111/j.1460-9568.2007.05505.x
Glenn, M. J., Kirby, E. D., Gibson, E. M., Wong-Goodrich, S. J., Mellott, T. J., Blusztajn, J. K., \& Williams, C. L. (2008). Age-related declines in exploratory behavior and markers of hippocampal plasticity are attenuated by prenatal choline supplementation in rats. Brain Research, 1237, 110-123. doi:10.1016/j.brainres.2008.08.049

Goodlett, C. R., \& Johnson, T. B. (1997). Neonatal binge ethanol exposure using intubation: Timing and dose effects on place learning. Neurotoxicology and Teratology, 19, 435-446. doi:10.1016/S08920362(97)00062-7

Gould, E., Farris, W., \& Butcher, L. L. (1989). Basal forebrain neurons undergo somatal and dendritic remodeling during postnatal development: A single-section Golgi and choline acetyltransferase analysis Developmental Brain Research, 46, 297-302. doi:10.1016/01653806(89)90293-9

Guimarais, M., Gregorio, A., Cruz, A., Guyon, N., \& Moita, M. A. (2011). Time determines the neural circuit underlying associative fear learning. Frontiers in Behavioral Neuroscience, 5, December 27 Article 89.

Guo-Ross, S. X., Clark, S., Montoya, D. A. C., Jones, K. H., Obernier, J., Shetty, A. K., ... Swartzwelder, H. S. (2002). Prenatal choline supplementation protects against postnatal neurotoxicity. The Journal of Neuroscience, 22, $\mathrm{RC} 195$.

Hamilton, G. F., Murawski, N. J., St. Cyr, S. A., Jablonski, S. A., Schiffino, F. L., Stanton, M. E., \& Klintsova, A. Y. (2011). Neonatal alcohol exposure disrupts hippocampal neurogenesis and contextual fear conditioning in adult rats. Brain Research, 1412, 88-101. doi:10.1016/ j.brainres.2011.07.027

Hunt, P. S., Levillain, M. E., Spector, B. M., \& Kostelnik, L. A. (2009). Post-training ethanol disrupts trace conditioned fear in rats: Effects of timing of ethanol, dose and trace interval duration. Neurobiology of Learning and Memory, 91, 73-80. doi:10.1016/j.nlm.2008.10.001

Hunt, P. S., \& Richardson, R. (2007). Pharmacological dissociation of trace and long-delay fear conditioning in young rats. Neurobiology of Learning and Memory, 87, 86-92. doi:10.1016/j.nlm.2006.06.003

McEchron, M. D., Bouwmeester, H., Tseng, W., Weiss, C., \& Disterhoft, J. (1998). Hippocampectomy disrupts auditory trace fear conditioning and contextual fear conditioning in the rat. Hippocampus, 8, 638-646. doi:10.1002/(SICI)1098-1063(1998)8:6<638::AID-HIPO6>3.0.CO; 2-Q

Meck, W. H., Smith, R. A., \& Williams, C. L. (1989). Organizational changes in cholinergic activity and enhanced visuospatial memory as a function of choline administered prenatally or postnatally or both. Behavioral Neuroscience, 103, 1234-1241. doi:10.1037/07357044.103.6.1234

Meck, W. H., Williams, C. L., Cermak, J. M., \& Blusztajn, J. K. (2008). Developmental periods of choline sensitivity provide an ontogenetic mechanism for regulating memory capacity and age-related dementia. Frontiers in Integrative Neuroscience, 1 (Article 7), 1-11.

Meck, W. H., \& Williams, C. L. (1997a). Characterization of the facilitative effects of perinatal choline supplementation on timing and temporal memory. Neuroreport, 8, 2831-2835. doi:10.1097/00001756199709080-00005

Meck, W. H., \& Williams, C. L. (1997b). Simultaneous temporal processing is sensitive to prenatal choline availability in mature and aged rats Neuroreport, 8, 3045-3051. doi:10.1097/00001756-199709290-00009

Meck, W. H., \& Williams, C. L. (2003). Metabolic imprinting of choline by its availability during gestation: Implications for memory and attentional processing across the lifespan. Neuroscience and Biobehavioral Reviews, 27, 385-399. doi:10.1016/S0149-7634(03)00069-1

Mellott, T. J., Williams, C. L., Meck, W. H., \& Blusztajn, J. K. (2004). Prenatal choline supplementation advances hippocampal development and enhanced MAPK and CREB activation. FASEB Journal, 18, 545547.

Micheau, J., \& Marighetto, A. (2011). Acetylcholine and memory: A long, 
complex and chaotic but still living relationship. Behavioural Brain Research, 221, 424-429. doi:10.1016/j.bbr.2010.11.052

Moon, J., Chen, M., Gandhy, S. U., Strawderman, M., Levitsky, D. A., Maclean, K. N., \& Strupp, B. J. (2010). Perinatal choline supplementation improves cognitive functioning and emotion regulation in the Ts65Dn mouse model of Down syndrome. Behavioral Neuroscience, 124, 346-361. doi:10.1037/a0019590

Nag, N., \& Berger-Sweeney, J. E. (2007). Postnatal dietary choline supplementation alters behavior in a mouse model of Rett syndrome. Neurobiology of Disease, 26, 473-480. doi:10.1016/j.nbd.2007.02.003

Napoli, I., Blusztajn, J. K., \& Mellott, T. J. (2008). Prenatal choline supplementation in rats increases the expression of IGF2 and its receptor IGF2R and enhances IGF2-induced acetylcholine release in hippocampus and frontal cortex. Brain Research, 1237, 124-135. doi:10.1016/ j.brainres.2008.08.046

Obernier, J. A., White, A. M., Swartzwelder, H. S., \& Crews, F. T. (2002). Cognitive deficits and CNS damage after a 4-day binge ethanol exposure in rats. Pharmacology, Biochemistry and Behavior, 72, 521-532. doi: 10.1016/S0091-3057(02)00715-3

Osborne, G. L., \& Butler, A. C. (1983). Enduring effects of periadolescent alcohol exposure on passive avoidance performance in rats. Physiological Psychology, 11, 205-208.

Pyapali, G. K., Turner, D. A., Williams, C. L., Meck, W. H., \& Swartzwelder, H. S. (1998). Prenatal dietary choline supplementation decreases the threshold for induction of long-term potentiation in young adult rats. Journal of Neurophysiology, 79, 1790-1796.

Pyapali, G. K., Turner, D. A., Wilson, W. A., \& Swartzwelder, H. S. (1999). Age and dose-dependent effects of ethanol on the induction of hippocampal long-term potentiation. Alcohol, 19, 107-111. doi:10.1016/ S0741-8329(99)00021-X

Quinn, J. J., Loya, F., Ma, Q., \& Faneslow, M. (2005). Dorsal hippocampus NMDA receptors differentially mediate trace and contextual fear conditioning. Hippocampus, 15, 665-674. doi:10.1002/hipo.20088

Quinn, J. J., Ma, Q. D., Tinsley, M. R., Koch, C., \& Fanselow, M. S. (2008). Inverse temporal contributions of the dorsal hippocampus and medial prefrontal cortex to the expression of long-term fear memories. Learning \& Memory, 15, 368-372. doi:10.1101/lm.813608

Quinn, J. J., Oommen, S. S., Morrison, G. E., \& Fanselow, M. S. (2002). Post-training excitotoxic lesions of the dorsal hippocampus attenuate forward trace, backward trace, and delay fear conditioning in a temporally specific manner. Hippocampus, 12, 495-504. doi:10.1002/ hipo. 10029

Ryan, S. H., Williams, J. K., \& Thomas, J. D. (2008). Choline supplementation attenuates learning deficits associated with neonatal alcohol exposure in the rat: Effects of varying the timing of choline administration. Brain Research, 1237, 91-100. doi:10.1016/j.brainres.2008.08.048

Sánchez, G., de Oliveira Alvares, L., Oberholzer, M. V., Genro, B., Quillfeldt, J., Costa da Costa, J., ... Kornisiuk, E. (2009). M M musca- $_{4}$ rinic receptors are involved in modulation of neurotransmission at synapses of Schaffer collaterals on CA1 hippocampal neurons in rats. Journal of Neuroscience Research, 87, 691-700. doi:10.1002/jnr.21876

Sandstrom, N. J., Loy, R., \& Williams, C. L. (2002). Prenatal choline supplementation increases NGF levels in the hippocampus and frontal cortex of young and adult rats. Brain Research, 947, 9-16. doi:10.1016/ S0006-8993(02)02900-1

Scheiderer, C. L., Smith, C. C., McCutchen, E., McCoy, P. A., Thacker, E. E., Kolasa, K., .. McMahon, L. L. (2008). Coactivation of $\mathbf{M}_{1}$ muscarinic and $\alpha 1$ adrenergic receptors stimulates extracellular signalregulated protein kinase and induces long-term depression at CA3-CA1 synapses in rat hippocampus. The Journal of Neuroscience, 28, 53505358. doi:10.1523/JNEUROSCI.5058-06.2008

Shors, T. J., Miesegaes, G., Beylin, A., Zhao, M., Rydel, T., \& Gould, E. (2001). Neurogenesis in the adult is involved in the formation of trace memories. Nature, 410, 372-376. doi:10.1038/35066584

Slotkin, T. A., Seidler, F. J., Qiao, D., Aldridge, J. E., Tate, C. A., Cousins, M. M., ... Spindel, E. R. (2005). Effects of prenatal nicotine exposure on primate brain development and attempted amelioration with supplemental choline or Vitamin C: Neurotransmitter receptors, cell signaling and cell development markers in fetal brain regions of rhesus monkeys Neuropsychopharmacology, 30, 129-144. doi:10.1038/sj.npp.1300544

Tees, R. C., \& Mohammadi, E. (1999). The effects of neonatal choline dietary supplementation on adult spatial and configural learning and memory in rats. Developmental Psychobiology, 35, 226-240. doi: 10.1002/(SICI) 1098-2302(199911)35:3<226::AID-DEV7>3.0.CO;2-H

Thomas, J. D., Garrison, M., \& O'Neill, T. M. (2004). Perinatal choline supplementation attenuates behavioral alterations associated with neonatal alcohol exposure in rats. Neurotoxicology and Teratology, 26, 35-45. doi:10.1016/j.ntt.2003.10.002

Thomas, J. D., La Fiette, M. H., Quinn, V. R. E., \& Riley, E. P. (2000). Neonatal choline supplementation ameliorates the effects of prenatal alcohol exposure on a discrimination learning task in rats. Neurotoxicology and Teratology, 22, 703-711. doi:10.1016/S08920362(00)00097-0

Thomas, J. D., O’Neill, T. M., \& Dominguez, H. D. (2004). Perinatal choline supplementation does not mitigate motor coordination deficits associated with neonatal alcohol exposure in rats. Neurotoxicology and Teratology, 26, 223-229. doi:10.1016/j.ntt.2003.10.005

Thomas, J. D., \& Tran, T. D. (2012). Choline supplementation mitigates trace, but not delay, eyeblink conditioning deficits in rats exposed to alcohol during development. Hippocampus. doi:10.1002/hippo. 20925

Villalobos, J., Rios, O., \& Barbosa, M. (2001). Postnatal development of cholinergic system in mouse basal forebrain: Acetylcholinesterase histochemistry and choline-acetyltransferase immunoreactivity. International Journal of Developmental Neuroscience, 19, 495-502. doi: 10.1016/S0736-5748(01)00034-X

Wagner, A. F., \& Hunt, P. S. (2006). Impaired trace fear conditioning following neonatal ethanol: Reversal by choline. Behavioral Neuroscience, 120, 482-487. doi:10.1037/0735-7044.120.2.482

Wong-Goodrich, S. J., Mellott, T. J., Glenn, M. J., Blusztajn, J. K., \& Williams, C. L. (2008). Prenatal choline supplementation attenuates neuropathological response to status epilepticus in the adult rat hippocampus. Neurobiology of Disease, 30, 255-269. doi:10.1016/ j.nbd.2008.01.008

Yang, Y., Liu, Z., Cermak, J. M., Tandon, P., Sarkisian, M. R., Stafstrom, C. E., .. . Holmes, G. L. (2000). Protective effects of prenatal choline supplementation on seizure-induced memory impairment. The Journal of Neuroscience, 20, RC109.

Yttri, E. A., Burk, J. A., \& Hunt, P. S. (2004). Intermittent ethanol exposure in adolescent rats: Dose-dependent impairment in trace conditioning. Alcoholism: Clinical and Experimental Research, 28, 14331436. doi:10.1097/01.alc.0000147657.51745.a7

Zeisel, S. H. (2004). Nutritional importance of choline for brain development. Journal of the American College of Nutrition, 23, 621S-626S.

Received January 25, 2012

Revision received May 4, 2012

Accepted May 7, 2012 